\title{
Emergency preparedness for accidental chemical spills from tankers in Istanbul Strait
}

\author{
M. Korçak ${ }^{1}$, C. E. Balas ${ }^{2}$, R. E. Kurt ${ }^{3}$ \& O. Turan ${ }^{3}$ \\ ${ }^{1}$ International Maritime Organization, UK \\ ${ }^{2}$ Civil Engineering Department, Gazi University, Turkey \\ ${ }^{3}$ Department of Naval Architecture Ocean and Marine Engineering, \\ University of Strathclyde, UK
}

\begin{abstract}
Istanbul Strait is one of the most important and dangerous maritime passages in the world. In this study, the hazards for possible accidents of the tankers carrying various chemicals through the Istanbul Strait were investigated and a significant risk was identified due to the intensive transportation of the chemicals. The purpose of this work is to define some risk control options in order to establish an efficient management system which can minimize the probability of accidents and hazardous effects of possible chemical spills to human life and the environment. The risk is assessed by using the Formal Safety Assessment Methodology of the International Maritime Organization. Following this methodology, hazards of accidents were identified through a questionnaire which is applied to a group of experts focussed on a passage of Istanbul Strait. In addition to this, a frequency analysis of the accidents was carried out on the defined sections along the strait using the accident database in order to determine the geographical distribution of the type and cause of the accidents. On the other hand, the maritime traffic of the Istanbul Strait was simulated using computer based software in order to investigate the effects of the local traffic on the passage. As a conclusion of the simulation the hot spots were defined as the potential locations for collisions. Also, the consequences of such probable accidents were evaluated by using different dispersion modelling software for the spilled chemicals. As a result, a comprehensive management system for preparedness and response to chemical spills in the Istanbul Strait was proposed by taking into account the current management system and response equipment.
\end{abstract}


Furthermore, a detailed economic analysis of the proposed system was also performed.

Keywords: Istanbul Strait, maritime accident, tanker, risk assessment, collision, chemical spill, oil spill, emergency, response, preparedness, simulation.

\section{Introduction}

The safety at sea is based on a set of accepted rules that are, in general, agreed upon through the International Maritime Organization (IMO). The IMO is a specialized agency of the United Nations which is responsible for developing measures to improve the safety and security of international shipping and to prevent marine pollution from ships. The IMO's main concern is to develop international treaties and other legislation concerning safety and marine pollution prevention. Much of maritime safety policy worldwide has been developed after serious accidents such as; Exxon Valdez, Erika, and Prestige. This approach was discontinued following the introduction of the Formal Safety Assessment Guideline (MSC-MEPC.2/Circ.12) in 1997. Formal Safety Assessment (FSA) was introduced by the IMO as a rational and systematic process for assessing the risk related to maritime safety, the protection of the marine environment and for evaluating the costs and benefits of IMO's options for reducing these risks. FSA should also provide support to, the IMO's decision-making process (Kontovas and Psaraftis [1]). In this study the transportation of dangerous chemicals (including crude oil) via tankers through the Istanbul Strait was investigated by using the FSA Methodology. The Strait of Istanbul, in particular, presents the greatest challenge for navigation as it flows through the heart of Istanbul, a city of over 15 million people and rich with thousands of years of history, which is declared as a "World Heritage City" by UNESCO. The Strait of Istanbul, the narrow waterway separating Europe from Asia, holds a strategic importance in maritime transportation. It is considered as one of the world's most congested and difficult-to-navigate waterways. Approximately 9000 tankers pass through the Istanbul Strait by carrying 130 million tonnes dangerous cargo annually [2]. The narrowness, bends, currents and densely populated shores make navigation quite dangerous in this waterway.

The Strait of Istanbul is approximately 17 nautical miles (NM) long; the average time for completing one passage is 1.7 hours. It takes several sharp turns, forcing the ships to alter course at least 12 times, sometimes executing turns of up to 80 degrees. There are roughly 128 ships passes through the strait on a daily average (Oral and Öztürk [3]). Additionally, on the vertical direction to this traffic there is also an intensive domestic ferry traffic between two sides of the Istanbul Strait mostly for passengers and cars. There are more than 1500 domestic daily ships passages taking place between the two sides of the strait [2]. There have been a number of catastrophic accidents in the Istanbul Strait in the past. The Independenta (1979) and the Nassia (1994) tanker accidents deeply affected the citizens of Istanbul and the environment by causing the death of 72 people and 115,000 tonnes of chemical spill to the marine environment. After these major spills, significant measures were taken in order to ensure the safe 
passage through the Istanbul Strait. Accordingly, Turkish Straits Regulation was established on 1998 which defined the passage rules. Similarly, the Vessel Traffic Information System was established in 2003 which controls the traffic by remote sensing radars. Furthermore, one way traffic regime was introduced on 2006 aiming to decrease the probability of collisions. However, accidents still occur in the Istanbul Strait. It was recorded that there were 228 shipping accidents in Istanbul Strait between 2006 and 2012 [4]. Therefore, this study is aiming to suggest a management system for Istanbul Strait which covers the mitigating measures to increase the following:

- the capability of preparedness;

- the capacity for emergency response operations to the chemical spills;

- $\quad$ the cleaning and rehabilitation measures after the spill.

This management system could be a key factor in decreasing the risk of a possible chemical spill from a tanker carrying dangerous chemicals.

\section{Methodology}

Ensuring navigational safety in Istanbul Strait and the protecting its coastal population and environment from ship sourced hazards are of great importance. It should be noted that, the amount of chemicals transported through Istanbul Strait is approximately 130 million tonnes per year [3] is far more than the annual capacity of Baku-Tbilisi-Ceyhan pipe line which is around 60 million tonnes or Kirkuk-Ceyhan pipeline which is around 83 million tonnes. On this occasion, a management system is recommended within this study which includes risk control options (RCO) for tanker accidents that may result in chemical spills. These recommended RCOs constitute an accident management system, which is defined specifically for the Istanbul Strait. This study starts with analysis of the accident probability and possible locations for a tanker accident through the Istanbul Strait. First, in order to analyse the passage and incident densities with respect to location, 16 parallel sections, which are 1 nautical mile apart from each other were created from north to south along the strait. 1st and the 16th sections are designed bigger when compared to others in order to capture the ship movements from different angels into the strait area. The environmental parameters like currents, sharp turns, shallow and narrow areas were analysed in each section in order to define the most difficult sections to navigate. On this context, a questionnaire was developed and implemented in order to capture expert opinions about the most dangerous sections of the Istanbul Strait. For that reason, experts were selected from maritime domain who are actively using the Istanbul Strait to navigate. Following the questionnaire a simulation modelling of the passage was created on PROMODEL software programme. The aim of this simulation was to define the probability of collision between the tankers and the domestic ferries. The traffic was simulated replicating the real traffic density of Istanbul Strait considering both the number of ships and the time of heavy traffic. Simulation modelling is an important tool which was used for risk assessment and collision probability modelling (Goerlandt and Kujala [5]). After running the simulations for a five year duration 
the collision probability of the tankers and the domestic ferries within each section was calculated. Also past accident statistics were investigated between 2006 and 2012 in order to define in which sections the accidents occurred more. These studies created a clear idea about the probability and possible location of a tanker accident along Istanbul Strait. After accident probability investigation, this study continues with the Formal Safety Assessment (FSA), which starts with the identification of hazards. Potential hazards involved in the passage of the Istanbul Strait were defined with a brainstorming session by using the accident statistics and an expert questionnaire. The main hazards during the passage were defined as; contact, collision, grounding, fire, explosion and structural failure. The main aim of first step was to define what can go wrong during the passage. The second step of FSA was a quantitative risk assessment, which aimed to find how likely these hazards occur as well as how severe the consequences could be. The risk is identified as the multiplication of the frequency and the consequence (severity). The tanker accident statistics between 1991 and 2008 are used for the calculations. The event tree methodology was used to create scenarios and calculate the risk summation by defining the frequency and consequence for each scenario. Also in order to better understand the severity of chemical spills, dispersion modelling of the most transported chemicals was done by utilising GNOME and ALOHA software programmes. The aim of dispersion modelling was to understand the physical movement of the chemicals in atmosphere and water. By this way, an estimation was done on the number of people, who could be effected from a chemical spill in Istanbul. In the last step, potential areas of improvement were identified and necessary RCO's were defined in order to create an accident management system for Istanbul Strait. Furthermore, the financial effect of this management system was evaluated in order to put forward the feasibility of implementation.

\section{Accident probability}

There are several analyses made in this study in order to assess the accident probability through Istanbul Strait. Figure 1 shows the created sections along the Istanbul Strait and the steps for assessing the accident probability.
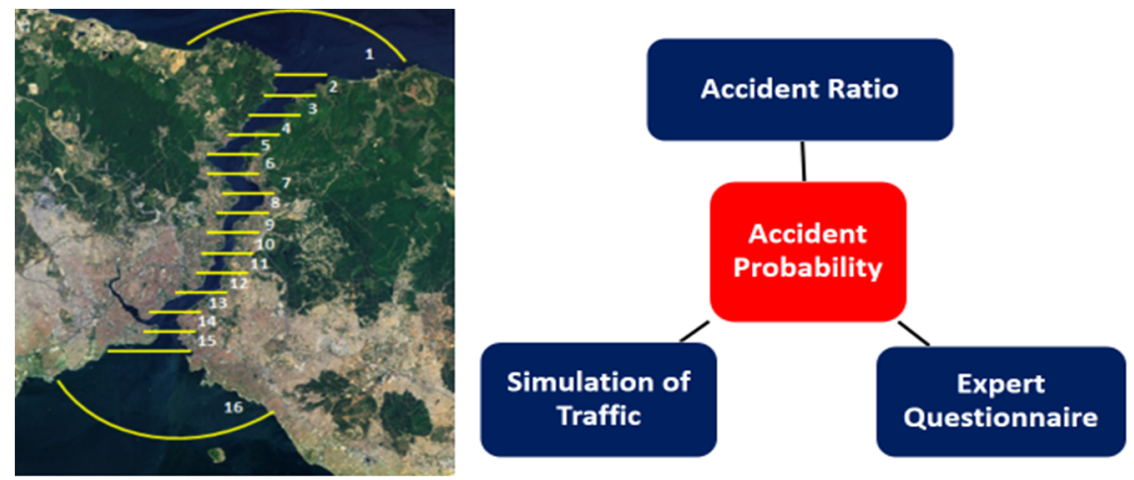

Figure 1: Defined sections on the Istanbul Strait. 
First of all, the accident ratio analysis was made and the distribution of the accidents along Istanbul Strait was defined. The second study was the simulation of the traffic and the collision probability was defined. The third study was an expert questionnaire which defines the navigational hazards.

\subsection{Accident ratio}

The accidents statistics between 2006 and 2012 in Istanbul strait were investigated and the accident ratio was calculated for each section by dividing the number of accidents to the ships passed on that section annually. The average accident ratios presented in figure 2 showed that the $1^{\text {st }}$ section has the highest accident ratio while other sections also have significant accident ratios. Although similar number of accident happened in the $1^{\text {st }}$ and $16^{\text {th }}$ sections the $1^{\text {st }}$ section has the highest accident ratio because of the less number of ship passes observed in the $1^{\text {st }}$ section. It should be known that there are more than 1500 domestic ships passages take place daily across the strait. This domestic traffic is flowing mostly between $9^{\text {th }}$ and $16^{\text {th }}$ sections which decreased the accident ratio numbers on these sections. On the other hand the $9^{\text {th }}$ and the $10^{\text {th }}$ sections are well known areas where the currents and sharp turns significantly affect the safety of navigation adversely. Also the $13^{\text {th }}$ section there is an intense domestic traffic exists on Beşiktaş and Üsküdar wharfs (sections 13).

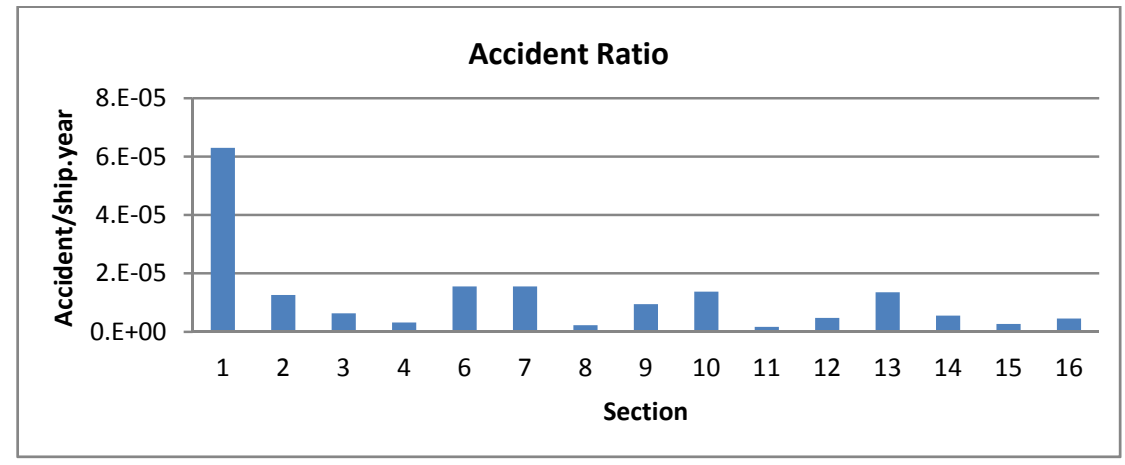

Figure 2: Accident ratio.

\subsection{Simulation of the passage}

The traffic of the Istanbul Strait was modelled by using the PROMODEL simulation software. The average speed for the ships navigating along the strait was defined as 10 Knots which is the current speed limit within Turkish Straits Regulation 1997. 128 ships were navigating along the strait daily and 25 of them were tankers. Only one direction passage was simulated and direction changed every 12 hours which is in line with the current implementation. On the other hand, from 14 wharfs 1529 domestic ferries were navigated by using the standard time tariffs with an average 8 knot speed. 16 junctions were defined where the ships and the domestic ferries cross their navigational route. During 
the simulation if a ship and a domestic ferry enters the junction at the same time then, this situation is counted as a crossing each other. These crossings are potentially dangerous activities because in these situations the safety of the navigation will heavily rely on the performance of the officer of the watch (human element) who is in charge of steering the vessel. The simulation was run for a 5 year duration and the simulations are repeated 6 times. The results showed that the $13^{\text {th }}$ and $14^{\text {th }}$ sections are the locations where most of the crossing between tankers and domestic ferries took place during the simulations. These sections are the locations where the busiest wharfs such as Beşiktaş, Üsküdar, Karaköy, Eminönü, and Harem (Sections 13 and 14) for domestic ferry traffic are located. There are also no junctions on the sections 1, 2, 3, 5, 9, 15 and 16 as the domestic ferries do not cross between the two sides of the strait and their route is parallel to the tankers navigating along the Istanbul Strait on these sections.

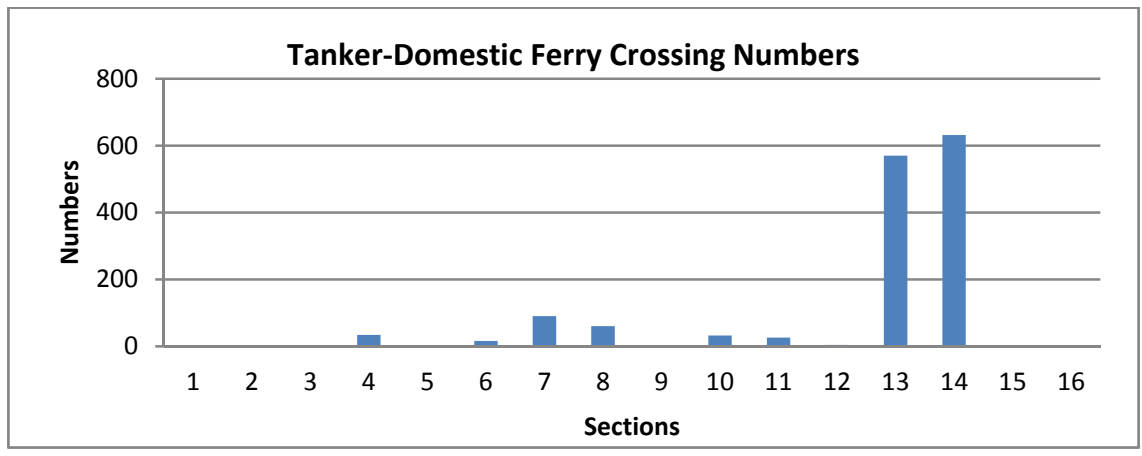

Figure 3: Simulation results.

\subsection{Expert questionnaire}

The expert questionnaire was applied to 13 participants, who were selected from maritime domain and actively have a role on pilotage or administration or using the strait to navigate. The questions asked them were about the environmental parameters like effect of currents, sharp turns, shallow and narrow areas for each section in order to define the most difficult sections to navigate. In addition, the effect of the domestic traffic and the probability of collision with domestic ferries were also asked. The experts evaluated the hazards by giving points between 1 and 10 for each parameter along each section while 1 is for smallest option and 10 is the biggest option to value the danger. The average values of the answers were reported in figure 4 . The results showed that the sections numbered 8,10 and 11 were defined as most dangerous sections by the experts. Furthermore, the accident ratio calculation results and the expert opinions were compared together also in figure 4 . The experts generally defined the dangers on the same sections where the accident ratio is also high. Only in three areas the opinions of the experts does not similar with the accident ratios. These are the North entrance of the Istanbul Strait (sections 1 and 2) where the accident ratio is 
high, the İstinye (section 8, 9) and the Kandilli, Çengelköy (sections 10, 11, 12) where the accident ratio is low. The sections $8,10,11$ and 12 are very narrow areas where it is difficult to navigate especially for big ships. Therefore, seafarers pay extra attention in these areas while navigating because of the well-known environmental and navigational challenges. These challenges motivate the sailors to take extra precautions and become more careful. This attitude can be evaluated as the reason of low accident ratios in dangerous areas. On the other hand, expert opinions for areas 1 and 2 contradict with the accident statistics as the accident ratio appears to be significantly higher compared to the experts' judgement. This can be attributed to the fact that seafarer navigating from open seas into the narrow passage may be failing to improve their situational awareness and alertness. Furthermore, due to the one way traffic system, number of stationary ships in section 1 may create additional navigational challenges. This requires further investigation.

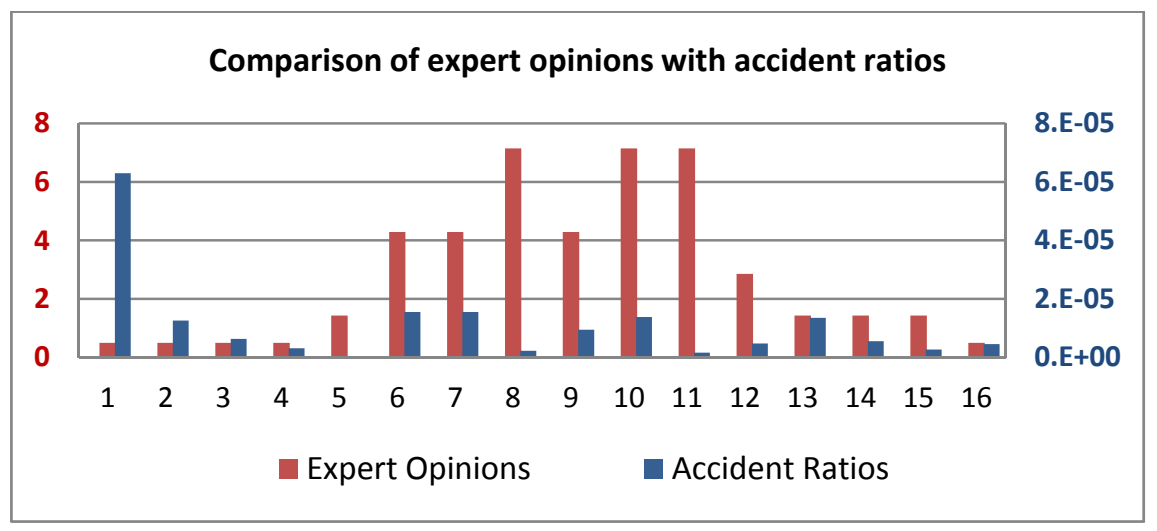

Figure 4: Questionnaire results.

\section{Risk assessment}

Risk was analysed by using the formal safety assessment methodology of International Maritime Organization. The data of tanker accidents in the world between 1991 and 2008 were used for this analysis. In order to create a relation between the tanker accident data in the world and the Istanbul Strait, the tanker accidents happened in narrow areas with intense traffic were used. Tankers in this section are investigated in two separate groups; chemical tankers and oil tankers. This segregation is done because the number of the oil tankers and the amount of the oil transported are much more than those in chemical tankers. Through this segregation it is aimed to investigate unique differences between the two aforementioned categories in detail. The event tree methodology was used to create scenarios and calculate the risk summation. The frequencies for each scenario were calculated using the ship accident data. When calculating the severities for each scenario, the data on loss of life in tanker accidents and the data about the amount of spills were used. In order to calculate the economic 
loss, several assumptions were made: a 40000 DWT tanker was used as a basis; price of the tanker was assumed as 60 million USD including cargo and bunker on board. The severity of accidents were analysed under three groups as small, medium and big accidents where the material damage assumed as 5\%, 30\% and $100 \%$ of the ship's price accordingly. Moreover, salvage, repair and operating costs were included. The economic loss is calculated in every scenario by using the aforementioned assumptions. In the event tree methodology the risk is calculated mathematically as shown in equation (1) by multiplying the probability $\left(\mathrm{P}_{\mathrm{i}}\right)$ and the consequence $\left(\mathrm{C}_{\mathrm{i}}\right)$ for each scenario. The total risk can be calculated with the summation of risks in all scenarios.

$$
\text { Risk }=\mathrm{C}_{1} \cdot \mathrm{P}_{1}+\mathrm{C}_{2} \cdot \mathrm{P}_{2}+\ldots . .+\mathrm{C}_{\mathrm{N}} \cdot \mathrm{P}_{\mathrm{N}}=\sum_{i=1}^{n} C i \cdot P i
$$

Tables 1 and 2 summarize the results of the risk analysis with respect to the tanker and accident types. The estimated frequencies for the accidents and the estimated risks for loss of life, loss of cargo and economical loses were calculated. In general, the potential life, cargo and economic losses for chemical tankers are estimated to be higher than the oil tankers. This is due to the higher accident frequencies of chemical tankers compared to the oil tankers. The

Table 1: Results of the risk assessment for chemical tankers.

\begin{tabular}{|c|c|c|c|c|}
\hline \multicolumn{5}{|c|}{ Chemical tankers } \\
\hline \multirow{2}{*}{ Accident type } & $\begin{array}{c}\text { Frequency } \\
\text { (accidents/ } \\
\text { ship.year) }\end{array}$ & $\begin{array}{c}\text { Potential loss } \\
\text { of lives (PLL) } \\
\text { (fatalities/ship. } \\
\text { year) }\end{array}$ & $\begin{array}{c}\text { Potential loss of } \\
\text { Cargo(PLC) } \\
\text { (tonnes/ship.year) }\end{array}$ & $\begin{array}{c}\text { Potential } \\
\text { Economic loss } \\
\text { (PEL) } \\
\text { (\$/ship.year) }\end{array}$ \\
\hline Contact & $4,66 \mathrm{E}-03$ & $1,35 \mathrm{E}-04$ & $4,30 \mathrm{E}-02$ & $7,19 \mathrm{E}+02$ \\
\hline Collision & $3,05 \mathrm{E}-03$ & $8,32 \mathrm{E}-05$ & $3,28 \mathrm{E}-02$ & $7,10 \mathrm{E}+02$ \\
\hline Grounding & $3,75 \mathrm{E}-03$ & $3,18 \mathrm{E}-05$ & $8,26 \mathrm{E}-02$ & $8,21 \mathrm{E}+02$ \\
\hline Fire & $2,31 \mathrm{E}-04$ & $5,32 \mathrm{E}-05$ & $9,83 \mathrm{E}-06$ & $1,80 \mathrm{E}+02$ \\
\hline Explosion & $8,77 \mathrm{E}-04$ & $1,15 \mathrm{E}-04$ & $1,09 \mathrm{E}-02$ & $2,21 \mathrm{E}+02$ \\
\hline Structural Failure & $3,24 \mathrm{E}-03$ & $2,43 \mathrm{E}-05$ & $1,98 \mathrm{E}-03$ & $1,86 \mathrm{E}+03$ \\
\hline
\end{tabular}

Table 2: $\quad$ Results of the risk assessment for oil tankers.

\begin{tabular}{|c|c|c|c|c|}
\hline \multicolumn{5}{|c|}{ Oil tankers } \\
\hline Accident type & $\begin{array}{c}\text { Frequency } \\
\text { (ship.year) }\end{array}$ & $\begin{array}{c}\text { Potential loss of } \\
\text { lives (PLL) } \\
\text { (fatalities/ship. } \\
\text { year) }\end{array}$ & $\begin{array}{c}\text { Potential loss of } \\
\text { Cargo (PLC) } \\
\text { (tonnes/ship.year) }\end{array}$ & $\begin{array}{c}\text { Potential } \\
\text { Economical loss } \\
\text { (PEL) } \\
\text { (\$/ship.year) }\end{array}$ \\
\hline Contact & $3,84 \mathrm{E}-04$ & $1,91 \mathrm{E}-05$ & $2,86 \mathrm{E}-02$ & $1,35 \mathrm{E}+02$ \\
\hline Collision & $3,74 \mathrm{E}-04$ & $2,17 \mathrm{E}-05$ & $1,68 \mathrm{E}-03$ & $1,14 \mathrm{E}+02$ \\
\hline Grounding & $4,60 \mathrm{E}-04$ & $1,02 \mathrm{E}-05$ & $5,35 \mathrm{E}-04$ & $1,47 \mathrm{E}+02$ \\
\hline Fire & $8,70 \mathrm{E}-05$ & $1,44 \mathrm{E}-05$ & $6,44 \mathrm{E}-04$ & $5,40 \mathrm{E}+01$ \\
\hline Explosion & $4,51 \mathrm{E}-05$ & $4,87 \mathrm{E}-06$ & $1,09 \mathrm{E}-02$ & $6,97 \mathrm{E}+01$ \\
\hline Structural Failure & $4,55 \mathrm{E}-04$ & $7,28 \mathrm{E}-06$ & $1,00 \mathrm{E}-03$ & $3,06 \mathrm{E}+02$ \\
\hline
\end{tabular}


difference in accident frequencies are also reflected on the economic loss values as the same economic assumptions were made for each tanker type.

\section{Modelling of spilled chemicals}

The behaviour of a substance spills at sea is altered during the first few hours. Predicting this behaviour is one of the most important stages in the development of a response strategy. In this study, the chemicals including crude oil from Istanbul Strait was classified due to their physical and chemical properties and also ranked due to the transportation amounts and frequencies of the transportation. The gases and evaporators were studied by using ALOHA software. The floaters were studied by GNOME software. These two software, which are practical and reliable tools, are the product of NOAA-National Oceanic and Atmospheric Administration of USA [8] and open for public use GNOME is proved to be valuable, efficient and low cost tools for oil spill modelling strategies (Almeida et al. [6]). This study was designed to focus on several spill scenarios along the Istanbul Strait and aimed to investigate the dispersion behaviour of the chemicals. It was also tried to make estimation on the number of people who could be affected from the chemicals in each scenario. The results showed for the floater chemicals which were modelled by GNOME that all the spills floats through the strait from north to south direction and reach to the Marmara Sea and disperse into the Marmara Sea. The more viscous ones disperse in smaller areas but less viscous ones disperse in larger areas as far as İzmit Bay (23 nautical miles away from the southern exit of the Istanbul Strait (Figure 5(b)).

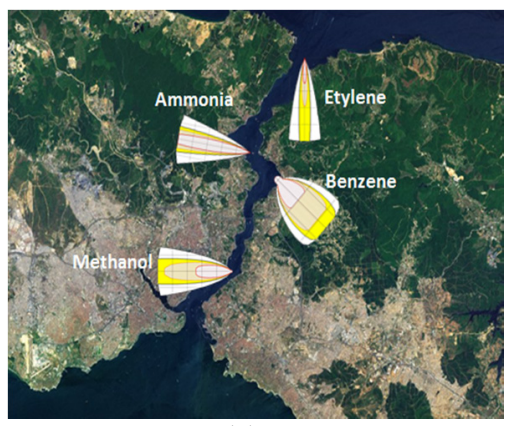

(a)

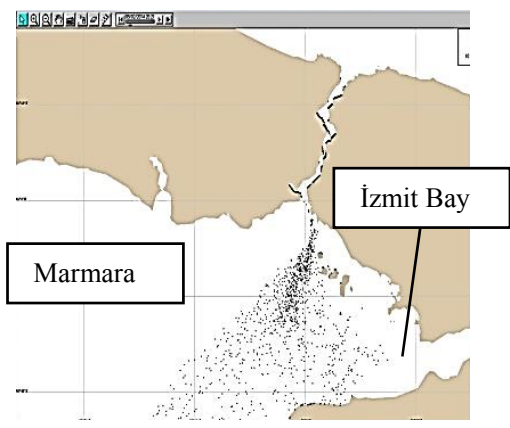

(b)

Figure 5: ALOHA (a) and GNOME (b) software outputs.

The results showed that the accident management in the Istanbul Strait should be organized by taking into account the dispersed chemicals into the Marmara Sea. The gases and evaporator chemicals were modelled by ALOHA software and the gas clouds produced by the software were imported into a digital map for several scenarios in order to analyse the extent of dispersion. The results in Figure 5(a) showed that the gas clouds will move significant distances on shore areas and can disperse between 7 and $18 \mathrm{~km}^{2}$. An estimation was made by using 
the density of population in Istanbul and it is calculated that between 4,000 and 40,000 people can be affected with respect to the scenarios created.

\section{Management of accidents}

Management of a chemical spill accident in Istanbul Strait should be evaluated under the disaster management coverage due to the fact that the management system should include preparedness activities, which covers civil protection measures. A complete set of measures were proposed within this study specifically for Istanbul Strait which is aimed to decrease the severity of the accidents resulted in chemical spills. The first proposed measure is to create an expert team consisting of 20 people which will work on a 24-hour standby basis at an emergency response centre located at the Istanbul Strait. The second proposed measure is to locate emergency response equipment containers on 13 wharfs along to Istanbul Strait, with equipment like response vessels, protective clothes, barriers, skimmers, absorbents etc. being defined by using the standards in the current legislation of Turkey and stockpiles in the world such as Oil Spill Response Limited (OSRL), Australian Marine Oil Spill Centre (AMOSC), and East Asia Response Ltd (EARL).

The third measure is to prepare an emergency response plan dedicated for Istanbul Strait, which is supported by modelling, communication and notification software. Fourth measure is to prepare awareness raising/training tools and a civil protection system in order to decrease the severity of spilled chemicals. It is believed that these measures will create an efficient accident management system in Istanbul Strait. Table 3 shows the proposed measures and estimation of the costs of these measures. The cost of chemical spill cannot be determined easily. The cost of the cleaning activities can be a small portion when we take into account the indirect costs to the economy and environment. After Exon Valdes

Table 3: Financial assessment.

\begin{tabular}{|c|c|c|c|c|}
\hline & & Cost TL & Cost USD & TOTAL USD \\
\hline \multirow{3}{*}{$\begin{array}{c}\text { Fixed } \\
\text { investment }\end{array}$} & Equipment & $6,321,550$ & $3,327,131$ & \multirow{3}{*}{$3,461,342$} \\
\hline & Software & 180,000 & 94,736 & \\
\hline & $\begin{array}{c}\text { Consultancy for plans, } \\
\text { etc. }\end{array}$ & 75,000 & 39,473 & \\
\hline & & $\begin{array}{c}\text { Cost } \\
\text { TL/Year }\end{array}$ & $\begin{array}{c}\text { Cost } \\
\text { USD/Year }\end{array}$ & $\begin{array}{c}\text { TOTAL } \\
\text { USD/Year }\end{array}$ \\
\hline \multirow{6}{*}{$\begin{array}{l}\text { Operational } \\
\text { cost }\end{array}$} & Personnel cost & 696,000 & 366,315 & \multirow{6}{*}{928,765} \\
\hline & Maintenance of eqp. & 101,000 & 53,157 & \\
\hline & Operation of centre & 160,000 & 84,210 & \\
\hline & Drills & 25,000 & 13,157 & \\
\hline & Raising awareness tools & 125,000 & 237,500 & \\
\hline & $\begin{array}{c}\text { Depreciation of fixed } \\
\text { investment }\end{array}$ & 657,655 & $1,249,544$ & \\
\hline
\end{tabular}


oil spill on 1989 in Alaska the court awarded \$287 million for actual damages and $\$ 5$ billion for punitive damages (Skinner and Reilly [7]). As a result, when the cost of the proposed system is compared with an actual spill, the results show that the proposed management system is feasible.

\section{Conclusion}

This study proposes reorganization in the region in order to establish a new accident management system which will focus on increasing the capabilities on preparedness activities to the accidents, increase the capabilities for effective and rapid response to chemical spills. In order to evaluate the accident probability and hot spots for accidents several analyses were conducted within this study investigating issue from different perspectives. These analyses demonstrated the environmental hazards for safety of navigation and the perception of the users on the threats for the strait. Moreover, the accident ratio study showed where the accidents are concentrated. Also, the simulation study showed the interaction of the tankers with domestic ferries that create potentially dangerous situations. The risk assessment by using the IMO's FSA methodology enables quantification of the risks for tankers passing through the Istanbul strait. Furthermore, in order to demonstrate the severity of an incident which involves a chemical spill, a basic dispersion modelling was used and the number of people and areas likely to be affected were estimated. This modelling study showed that a potential chemical spill can cause a disaster because of the estimated number of effected people. It was considered as important to demonstrate the amount of financial need to establish the proposed management system. The proposed system can be categorised as an enhancement of the current system which should not be evaluated as a new system. This feature is the key element to decrease the need for budget and make it practical to start implementations in a short time period. Estimated costs of establishing the proposed system can be considered as feasible for such an important region. However it also needs to be noted that success of such accident management systems heavily rely up on the strong administrative support due to the fact that a significant legislative revision will be required. This study is a step towards evaluating the hazards of tanker accidents and chemical spills for Istanbul Strait and proposes an enhancement on the current system which can be implemented easily and in a cost effective manner.

\section{References}

[1] Kontovas, A. \& Psaraftis, H. Formal Safety Assessment: A Critical Review. Marine Technology, 46(1), 45-59, 2009.

[2] Ministry of Transport, Maritime Affairs and Communications of Turkey Maritime Trade Statistics 2014 Turkey, pp. 10-100, 2014.

[3] Oral, N. \& Öztürk, B. (eds). The Turkish Straits maritime safety, legal and environmental aspects, İstanbul: TÜDAV publications, 66-81, 2006. 
[4] Maritime Accident Statistics 2014 published by Ministry of Transport, Maritime Affairs and Communications www.denizticareti.gov.tr

[5] Goerlandt, F. \& Kujala, P. Traffic simulation based ship collision probability modeling. Reliability Engineering and System Safety, 1(96), 91-107, 2011.

[6] Almeida, M. \& Villareal, M. \& Pereira, J. \& Otero, P. \& Girano, M. \& Zhang, X. \& Hetland, R. Efficient tools for marine operational forecast and oil spill tracking. Marine Pollution Bulletin, 1(71), 139-151, (2013).

[7] Skinner, S.K. \& Reilly, W.K. (eds). The Exon Valdez Oil Spill a Report to the President. The National Response Team 1989.

[8] NOAA, http://response.restoration.noaa.gov

[9] Modeling Risk in the Dynamic Environment of Maritime Transportation Proceedings of the 2001 Winter Simulation Conference Merrick, M. \& Dorp, R., 1(1), 123-130, 2001.

[10] Köse, E. \& Başar, E. \& Demirci, E. \& Güneroğlu, A. \& Erkebay, Ş. Simulation of marine traffic in Istanbul Strait. Simulation Modelling Practice and Theory, 1(11), 597-608, 2003.

[11] Montewka, J. \& Goerlandt, F. \& Kujala, P. On a systematic perspective on risk for formal safety assessment FSA. Reliability Engineering and System Safety, 1(127), 77-85, 2014.

[12] Neuparth, T. \& Moreira, S.M. \& Santos, M. M. \& Reis-Henriques, M.A. Hazardous and Noxious Substances (HNS) in the marine environment: Prioritizing HNS that pose major risk in a European context. Marine Pollution Bulletin, 1(62), 21-28, 2011.

[13] Otay, N.E. \& Özkan, Ş. Stochastic Prediction of Maritime Accidents in the Strait of Istanbul. Proc. of the 3rd Intl Conf on Oil Spills in the Mediterranean and Black Sea Regions İstanbul 2003.

[14] Plant, G. The Turkish Straits and tanker traffic: an update. Marine Policy, 1(24), 193-214, 2000.

[15] Ulusçu, Ö. S. \& Özbaş, B. \& Altık, T. \& Or, İ. (eds). Risk Analysis of Transit Vessel Traffic in the Strait of İstanbul. Research Project $104 Y 207$ and BAP (Scientific Research Projects Fund of Bogazici University) through the Research Project 07M104, İstanbul: TÜBİTAK, 1-100, 2008.

[16] Van Dorp, J. R. \& Merrik, J.R.W. \& Harrald, J.R. \& Mazzuchi, T.A. \& Grabowski, M. Risk Management Procedure for the Washington State Ferries. Risk Analysis, 1(21), 1-9, 2001.

[17] Wang, J. \& Foinikis, P. Formal safety assessment of containerships. Marine Policy, 1(25), 14-157, 2001.

[18] Yurtören, C. \& Aydoğdu, V. Risk Analysis of Congested Areas of Istanbul Strait via Ship Handling Simulator. Proc. of the 11th WSEAS International Conference on Automatic Control, Modelling and Simulation. 1(1), 146$149,2012$. 